\title{
Effect of Die Spacer Thickness on the Fracture Resistance of CAD/CAM Lithium Disilicate Veneers on Maxillary First Premolars
}

\author{
Sherine Mohamed Farag (D) \\ Mona Mohamed Ghoneim \\ Rania Reda Afifi \\ Conservative Dentistry Department, \\ Faculty of Dentistry, Alexandria, \\ University, Alexandria, Egypt
}

\begin{abstract}
Objective: The purpose of this study was to compare the fracture resistance of ceramic veneers with digital die spacer settings at $20 \mu \mathrm{m}, 40 \mu \mathrm{m}$, and $100 \mu \mathrm{m}$.

Materials and Methods: Eighteen sound maxillary first premolars were divided into three groups $(n=6)$ according to their digital die spacer settings: group $A=20 \mu \mathrm{m}$, group $B=40 \mu \mathrm{m}$, group $C=100 \mu \mathrm{m}$. Each tooth was prepared to a depth of $0.5 \mathrm{~mm}$ to receive lithium disilicate veneers (IPS e.max CAD, Ivoclar Vivadent). All groups were thermocycled (2500 cycles at $5-55^{\circ} \mathrm{C}$ ) and subjected to fracture resistance test using a universal testing machine until failure. Failure modes were examined using a stereomicroscope.

Results: The values $(\mathrm{N})$ for group $\mathrm{A}=1181.34 \pm 301.33$, group $\mathrm{B}=1014.29 \pm 291.12$, and group $\mathrm{C}=841.89 \pm 244.59$. One-way ANOVA showed no statistical difference among the three groups $(\mathrm{p}=0.145)$. However, chi-square test showed that a significant difference was present in the modes of failure ( $\mathrm{p}=0.009$ ). Tukey's post hoc test indicated that the failure modes of group A were statistically different from those of group $\mathrm{C}$, showing $83.3 \%$ adhesive failure for group A compared to $0 \%$ adhesive failures in group C. A p-value of $\leq 0.05$ was considered as statistically significant.
\end{abstract}

Conclusion: Digital die spacer thickness did not influence the mean fracture resistance values of $\mathrm{CAD} / \mathrm{CAM}$ lithium disilicate veneers. However, the way the failure occurred differed significantly at various die spacer thicknesses.

Keywords: fracture resistance, die spacer, lithium disilicate CAD veneers, CAD/CAM, cement thickness, cement space

\section{Introduction}

With the advances in ceramic, bonding procedures, and minimally invasive preparations, laminate veneers are now considered a reliable treatment choice. Despite their mostly predictable prognosis, ceramic veneers are not immune to failure. Laminate veneers are prone to debonding, marginal discoloration, periodontal complications, caries, tooth fracture, and fracture of the restoration itself. Among these, fractures seem to be one of the most common failures. ${ }^{1,2}$

In terms of durability of the veneer, cementation undoubtedly plays a key role. Resin cements present numerous advantages when it comes to the cementation of ceramic veneers. They tend to strengthen both the tooth surface and the ceramic. ${ }^{3}$ The increased flexural strength comes from the porcelain-resin hybrid layer resulting from the interpenetration of the resin in the etched porcelain surface. Moreover, light-cured resin-based luting agents are usually indicated as they have improved
Correspondence: Sherine Mohamed Farag Conservative Dentistry Department, Faculty of Dentistry, Alexandria University, 13 Champolion St, Azarita, Alexandria, Egypt Tel +20 I55235I433

Email sherine.m.farag@gmail.com 
color stability compared to dual-cured agents, and for the high degree of conversion achieved on light activation. ${ }^{4}$

Different materials used in ceramic veneers possess different properties. Careful choice of the appropriate material is therefore important. Stress concentration tends to increase as the elastic modulus of the cement and ceramic increases. ${ }^{5}$

The longevity of ceramic restorations depends not only on the type of cement used, but also on the close proximity between the restoration and tooth substrate. ${ }^{6}$ Close adaptation of the veneer to the tooth surface is essential, as the composite resin is the weakest link in this triple substrate complex. ${ }^{7}$ Clearance between the tooth surface and veneer is crucial to allow space for the luting cement, as several studies have shown that direct placement of the restoration on the tooth surface results in lower bond strengths. ${ }^{8,9}$ The traditional method of providing this space is manually, through the application of paint-on die spacer. As dentistry has evolved to incorporate computer-aided design and computer-aided manufacturing (CAD/CAM) technologies, die spacer settings can be set digitally. The studies on the effect of cement thickness and ceramic veneers specifically with regard to fracture resistance are rather limited. Most studies on this subject have focused on complete coverage posterior restorations. ${ }^{10,11}$ Therefore, the aim of this study was to shed light on the subject with regard to laminate veneers. The null hypothesis stated that digital die spacer settings do not affect the fracture resistance of CAD/CAM lithium disilicate veneers.

\section{Materials and Methods Tooth Specimen Preparation}

The protocol for this research was approved by the Commission of Medical Ethics of Alexandria University (approval number: 012403/2020). Eighteen sound permanent human maxillary first premolars were extracted for orthodontic purposes. The patients whose premolars were used in this research provided informed consent in accordance with the Declaration of Helsinki.

The premolars were then cleaned from any calculus with an ultrasonic scaler. For disinfection, they were kept in $0.2 \%$ thymol solution for 7 days to destroy any remaining microorganisms. The teeth were then stored in distilled water. Afterwards, each tooth was marked 2-mm beneath the cementoenamel junction by using a periodontal probe. The roots were coated with a 0.3 -mm-thick layer of wax until the aforementioned mark to mimic the periodontal space. The specimens were inserted, with the occlusal surface facing upward, into self-cure acrylic resin in a custom-made copper mold with a diameter of $14 \mathrm{~mm}$ and a length of $20 \mathrm{~mm}$. The teeth and wax were removed from the acrylic blocks, and a single layer of polyether adhesive (Polyether Adhesive,3M ESPE, GmbH, Neuss, Germany) was applied on the roots and let to dry completely. Polyether impression material (Impregum Soft, 3M ESPE, GmbH, Neuss, Germany) was then applied over the roots before the teeth were reinserted into the acrylic block. A sharp blade was used to remove excess impression material. ${ }^{12}$

\section{Tooth Surface Preparation and Veneer Fabrication}

Each tooth was prepared to a depth of $0.5 \mathrm{~mm}$ into the enamel with a high-speed handpiece and depth-limiting and tapered diamond burs of medium grit (Microdont, USA). The preparation involved a $0.5-\mathrm{mm}$ reduction of the buccal surface and buccal cusp. The reduction extended $1 \mathrm{~mm}$ over the occlusal surface of the buccal $\operatorname{cusp}^{12}$ (Figure 1).

The specimens were sprayed with titanium dioxide powder spray (SHERA Werkstoff-Technologie GmbH \& Co.KG, Lemförde, Germany) and scanned using an extraoral Vinyl scanner (Smart optics, Bochum, Germany). Exocad software (Exocad, GmbH, Darmstadt, Germany) was used to design the lithium disilicate veneers (IPS e. max CAD, Ivoclar Vivadent, Schaan, Liechtenstein). The design was transferred to a CAM milling unit (CEREC 3 CAD/CAM milling machine; Sirona Dental Systems, $\mathrm{GmbH}$, Bensheim, Germany). The blocks (high translucency, shade A1, size C14) were loaded into the milling machine and wet milled using diamond burs. The partially crystallized veneers were then crystallized using Programmat p310 (Ivoclar Vivadent, Schaan, Liechtenstein). Glazing and finishing were done according to the manufacturer's instructions. The veneers had a uniform thickness of $0.5 \mathrm{~mm}$. The specimens were divided into three groups, according to their respective digital die spacer settings_Group $\mathrm{A}=20$ microns $(\mu \mathrm{m})$, group $\mathrm{B}=40 \mu \mathrm{m}$, and group $\mathrm{C}=100 \mu \mathrm{m} .{ }^{13}$

\section{Surface Treatment of Veneers}

$8 \%$ hydrofluoric acid (Dentobond etching gel, Itena, France) was used to etch the internal surfaces of the veneers. The etching gel was applied for 60 seconds, 


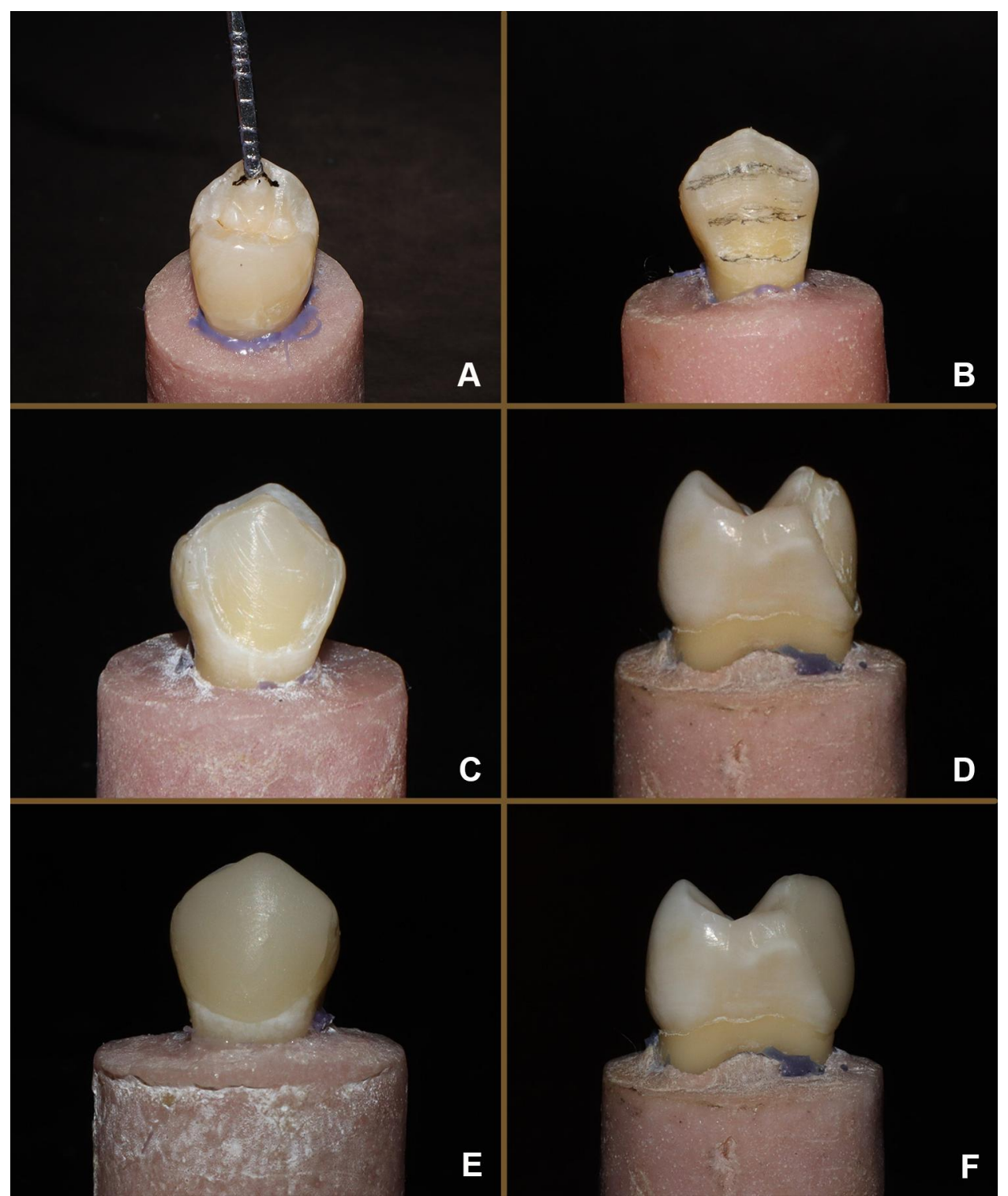

Figure I Specimens preparation. (A) Marking of I mm of buccal cusp overlap for preparation with periodontal probe. (B) $0.5 \mathrm{~mm}$ depth orientation grooves on labial surface. (C) Veneer preparation buccal view. (D) Veneer preparation proximal view. (E) Veneer cementation buccal view. (F) Veneer cementation proximal view.

then thoroughly rinsed with a water spray before being gently dried with oil-free air. Finally, the etched surfaces were primed with a single coat of ceramic primer (RelyX ceramic primer, 3M ESPE, St. Paul, MN, USA) for 60 seconds, then air-dried before cementation. ${ }^{12}$

\section{Surface Treatment of Tooth Surface}

The prepared enamel surfaces were etched using 37\% phosphoric acid (N-etch gel, Ivoclar Vivadent, Schaan, Liechtenstein) for 15 seconds, then washed thoroughly with a water stream for 10 seconds; the excess water was removed using a cotton pellet. Two layers of universal adhesive (Single bond universal adhesive, 3M ESPE,
St. Paul, MN, USA) were applied using a disposable applicator onto the etched enamel surfaces. Compressed water- and oil-free air was used to disperse the adhesive into a uniform layer over the enamel surface. ${ }^{12}$

\section{Cementation of Veneers}

A layer of resin cement (RelyX Veneer, 3M ESPE, St. Paul, MN, USA) was placed on the internal surface of the ceramic veneer, which was then placed on the tooth surface by applying gentle finger pressure. The veneer was tack-cured for 2 seconds to enable removal of excess cement with an explorer tip. The veneers were then lightcured for 40 seconds in four straight opposite directions to 
ensure complete polymerization using a light emitting diode unit with a light intensity of $1200 \mathrm{~mW} / \mathrm{cm}^{2}$ (Elipar ${ }^{\mathrm{TM}}$ FreeLight 2, 3M ESPE, St.Paul, MN, USA) (Figure 1). The artificial aging process was achieved through thermocycling that comprised 2500 cycles in water baths ranging from 5 to $55^{\circ} \mathrm{C}^{8,12}$

\section{Fracture Resistance Test}

A universal testing machine was used (Instron 3345, Instron Corporation, Canton, MA, USA) to test for fracture resistance. The test was performed with a speed of $0.5 \mathrm{~mm} / \mathrm{min}$ using a $2 \mathrm{kN}$ maximum load perpendicular to the buccal cusp tip of the veneers, until complete or partial fracture of the samples ${ }^{12}$ (Figure 2).

\section{Failure Mode Assessment}

A stereomicroscope (SZ114STR, Olympus, Japan) at $18 \times$ magnification was used to determine the mode of failure.

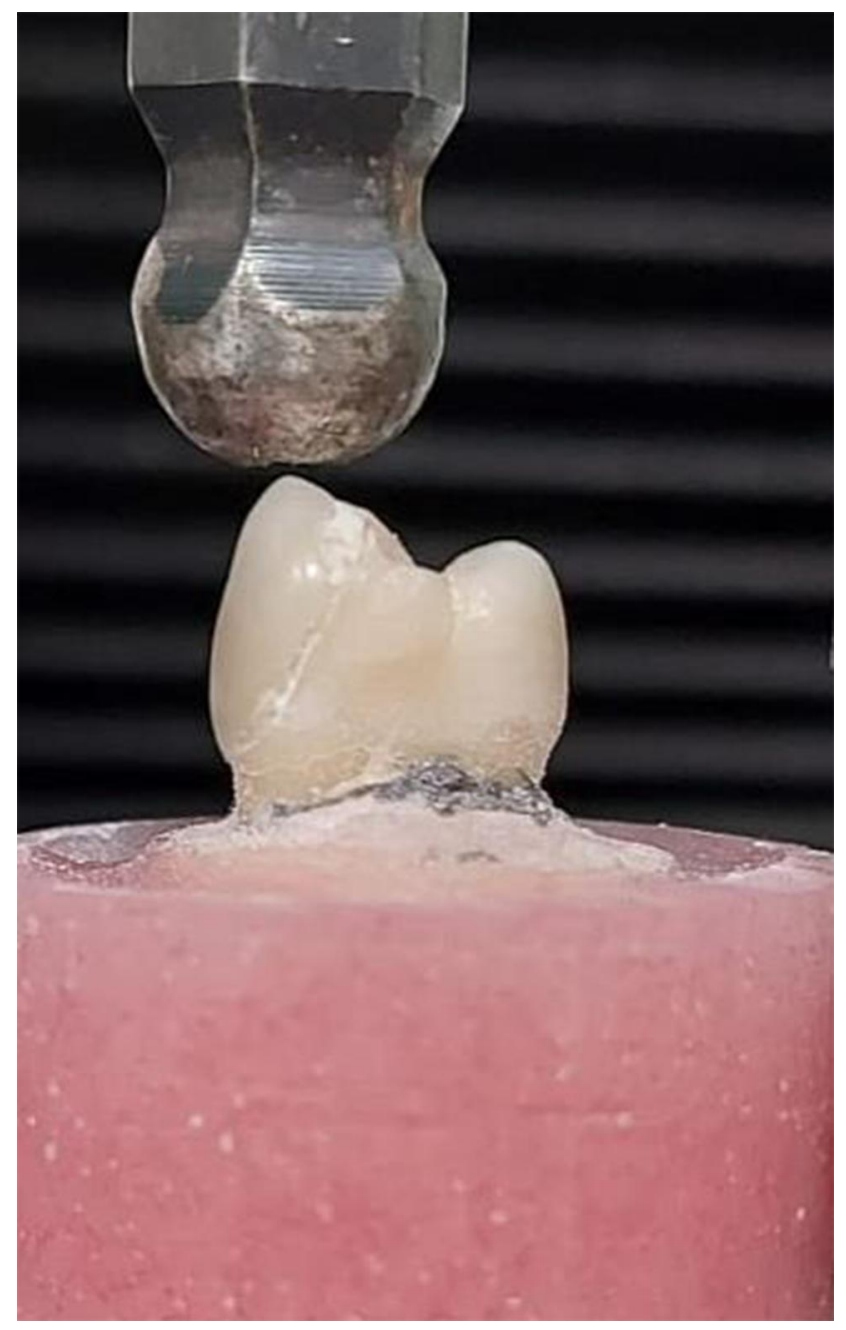

Figure 2 Fracture resistance testing with universal testing machine.
Failure modes were divided into three main types, namely adhesive, cohesive, or mixed, according to the percentage of bonded material still present on the tooth surface. Cohesive failures occurred if $>75 \%$ of luting resin remained on the enamel; adhesive failures, if $<25 \%$ remained; and mixed type failure, if between $25 \%$ and $75 \%$ of the resin was still adhered to the enamel ${ }^{14}$ (Figure 3 ).

\section{Statistical Analysis}

Data were analyzed using IBM SPSS statistical software (version 25; IBM Corporation, Armonk, NY, USA).

The sample size was estimated assuming 5\% alfa error and $80 \%$ study power. Based on a previous study, ${ }^{15}$ a standardized effect size in fracture resistance of 2.144 was assumed to detect the difference between $40 \mu \mathrm{m}$ and $100 \mu \mathrm{m}$. By comparing these two groups, to ensure the study power, using a standard deviation of 339.51, a sample of 5 specimens per group was required and increased to 6 to make up for processing errors. Total sample $=$ number per group $\times$ number of groups $=6 \times$ $3=18$ specimens.

Significance level was set at 0.05 . Normality was checked using Shapiro-Wilk test and box plot. Fracture resistance was normally distributed and presented using mean and standard deviation.

Type of fractures were presented using count and percent. Differences between the groups regarding the quantitative data of fracture resistance were assessed using one-way ANOVA followed by Tukey's post hoc test. The type of fracture (qualitative data) was compared using chi-square test.

\section{Results}

The mean values and standard deviations of the fracture resistance test are shown in Table 1 and Figure 4. The 20$\mu \mathrm{m}$ group (group A) showed the highest fracture resistance, while the $100-\mu \mathrm{m}$ group (group C) showed the lowest. However, one-way ANOVA $(\mathrm{p} \leq 0.05)$ indicated no statistically significant difference among the three groups.

Chi-square test indicated a significant difference in the distribution of failure modes (Figure 5). Tukey's post hoc test indicated the difference to be present between groups $\mathrm{A}$ and $\mathrm{C}$ (Table 2). Group A showed significantly higher adhesive failure $(83.3 \%)$ than group $\mathrm{C}(0 \%)$.

\section{Discussion}

Whether cement thickness has a significant effect on the fracture resistance of restorations remains debatable. This 


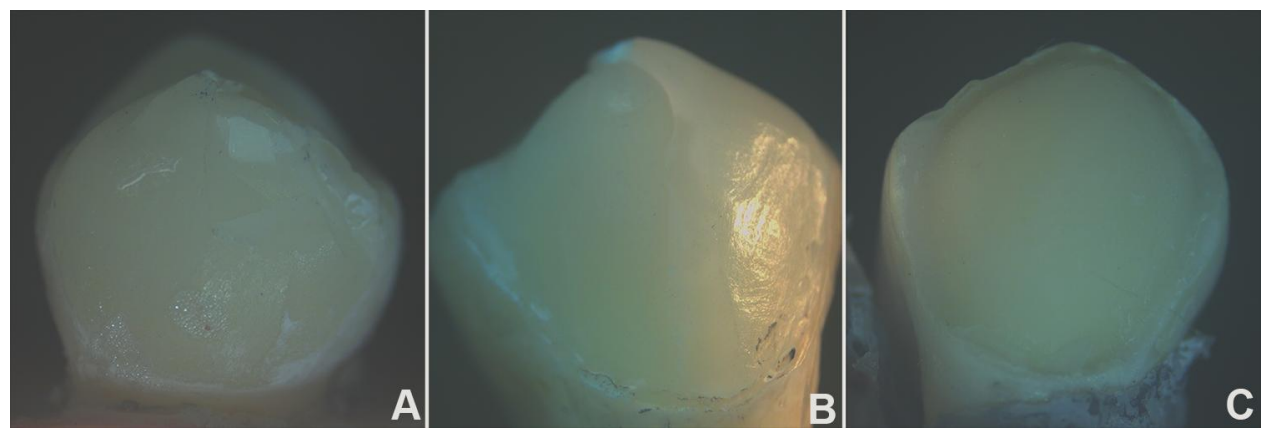

Figure 3 Stereomicroscopic analysis of failure modes at 18× magnification. Types of failure modes: (A) cohesive, (B) mixed, (C) adhesive.

study attempted to clarify this topic. The results of this study indicate that cement thickness does not affect the fracture resistance of $\mathrm{CAD} / \mathrm{CAM}$ lithium disilicate veneers. Hence, the null hypothesis was accepted. Sagsoz and Yanıkoglu, who compared the fracture resistance of e. max CAD monolithic crowns with cement thicknesses of $30 \mu \mathrm{m}, 90 \mu \mathrm{m}$, and $150 \mu \mathrm{m}$ found no significant difference in fracture resistance among the three groups. ${ }^{10}$ This phenomenon can be attributed to a reduced crack propagation when cement thicknesses are lower than $300 \mu \mathrm{m}$, as explained by Scherrer et al. ${ }^{16}$ The study found that fracture resistance decreased as cement thickness increased; however, the combined effects of acid-etching and application of silane provide a bond strength between the cement and ceramic substrates which can only be jeopardized when the cement thickness reaches $300 \mu \mathrm{m}$. According to Venturini et al, cement thicknesses of $50 \mu \mathrm{m}, 100 \mu \mathrm{m}$, and $300 \mu \mathrm{m}$ do not seem to influence the fatigue behavior of leucite crowns. ${ }^{17}$ The findings of this previous study show that the cement space configuration in the $\mathrm{CAD} /$ CAM software was not identical to the final cement thickness. The $50 \mu \mathrm{m}$ group actually had a cement thickness of $120.4 \mu \mathrm{m}$, while the $100-$ and $300-\mu \mathrm{m}$ groups presented a thickness of 174.9 and $337.2 \mu \mathrm{m}$, respectively. Moreover, different thicknesses were observed beneath the cusps and central fossa of the same restoration. This

Table I Fracture Resistance Means (N) and Standard Deviations (SD)

\begin{tabular}{|l|l|l|l|l|}
\hline $\begin{array}{l}\text { Digital Die } \\
\text { Spacer } \\
\text { Thickness }\end{array}$ & $\begin{array}{l}\mathbf{2 0} \\
\text { Microns } \\
(\mathbf{n}=6)\end{array}$ & $\begin{array}{l}\mathbf{4 0} \\
\text { Microns } \\
(\mathbf{n}=6)\end{array}$ & $\begin{array}{l}100 \\
\text { Microns } \\
(\mathbf{n}=6)\end{array}$ & $\begin{array}{l}\text { F Test } \\
(\boldsymbol{P} \text { value) }\end{array}$ \\
\hline Mean (SD) & 1181.34 & $\begin{array}{l}1014.29 \\
(291.12)\end{array}$ & $\begin{array}{l}841.89 \\
(244.59)\end{array}$ & $\begin{array}{l}2.203 \\
(0.145)\end{array}$ \\
\hline
\end{tabular}

Notes: One-way ANOVA. Significance level was set at $p \leq 0.05$.

Abbreviations: SD, standard deviations; $P$ value, probability value; $N$, Newton. would possibly explain the lack of statistical significance in the results. Milling burs may have difficulty in reproducing the precise and fine details of the intaglio surface of a restoration. In addition, preparation angles, type and diameter of the milling bur, and the scanning process may result in a larger internal gap. ${ }^{18}$ Regarding stress distribution, Tribst et al found that cement thicknesses of $100 \mu \mathrm{m}, 200 \mu \mathrm{m}$, and $300 \mu \mathrm{m}$ did not significantly affect the mechanical performance of occlusal veneers, as stresses were mostly concentrated in the restoration itself, rather than the cement. ${ }^{19}$ In contrast, May et al found that among cement thicknesses of $50 \mu \mathrm{m}, 100 \mu \mathrm{m}, 300$ $\mu \mathrm{m}$, and $500 \mu \mathrm{m}$, the highest strengths were found in the 50-100 $\mu \mathrm{m}$ range. ${ }^{20}$ The authors attributed the lower performance of the $\mathrm{CAD} / \mathrm{CAM}$ ceramic crowns with thicker cement spaces to the high polymerization shrinkage stresses within the cement. Moreover, in a finite element analysis conducted by Liu et al where cement thicknesses ranged from 10 to $180 \mu \mathrm{m}$, the results showed that failure began to occur in cement thicknesses greater than 50 $\mu \mathrm{m} .{ }^{13}$ This might be attributed to the considerable differences in the elastic modulus of the resin cement and that of the ceramic veneer, which were $6,000 \mathrm{MPa}$ and 70,000 $\mathrm{MPa}$, respectively. The authors concluded that the optimum cement thickness should be no greater than $50 \mu \mathrm{m}$. The present study reflected similar results to those of Karntiang and Leevailoj, who compared the fracture strengths of $0.5-\mathrm{mm}$ and $1-\mathrm{mm}$ thick veneers when their cement thicknesses varied between 30 and $100 \mu \mathrm{m} .{ }^{15}$ Compared to the fracture strengths of 1-mm-thick veneers, those of 0.5 -mm-thick veneers remained unaffected. The authors speculated that these results were likely because a $0.5-\mathrm{mm}$ ceramic thickness is so thin that the effect of cement thickness cannot be easily discerned. On the other hand, 1-mm-thick veneers exhibited significantly lower fracture strengths at $100 \mu \mathrm{m}$. When a ceramic restoration 


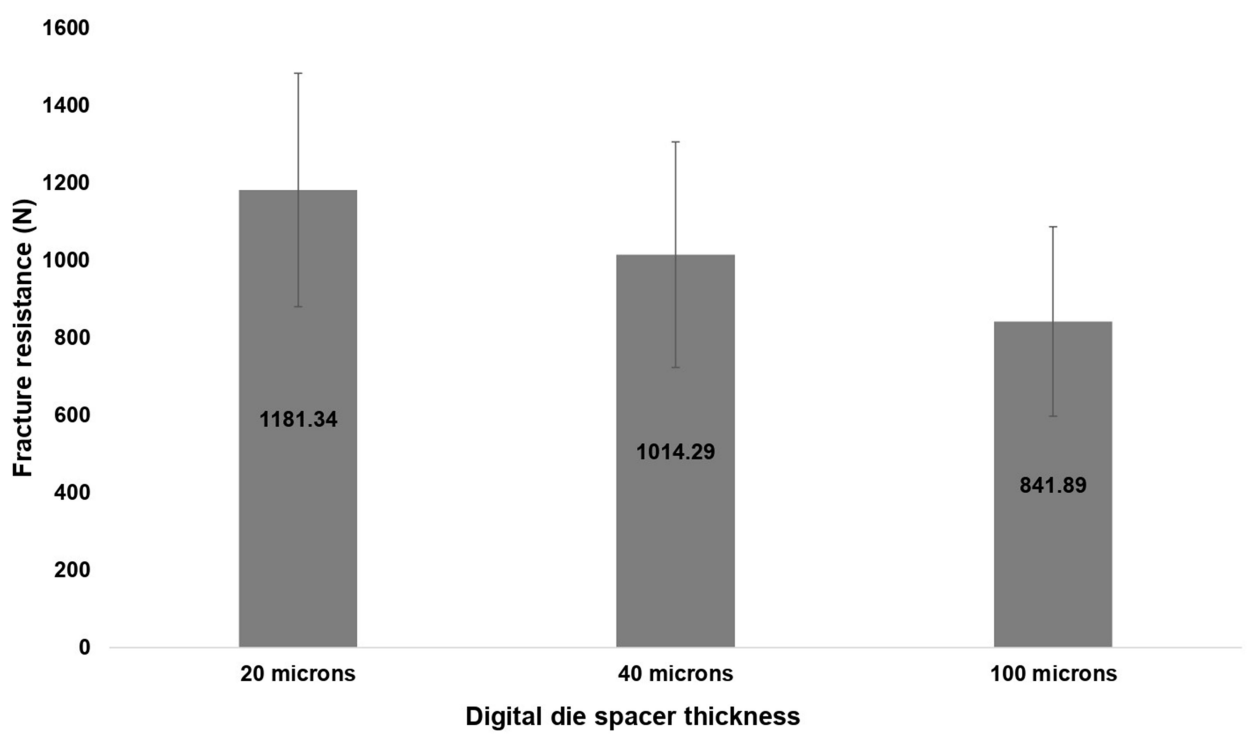

Figure 4 Fracture resistance means and standard deviations.

100

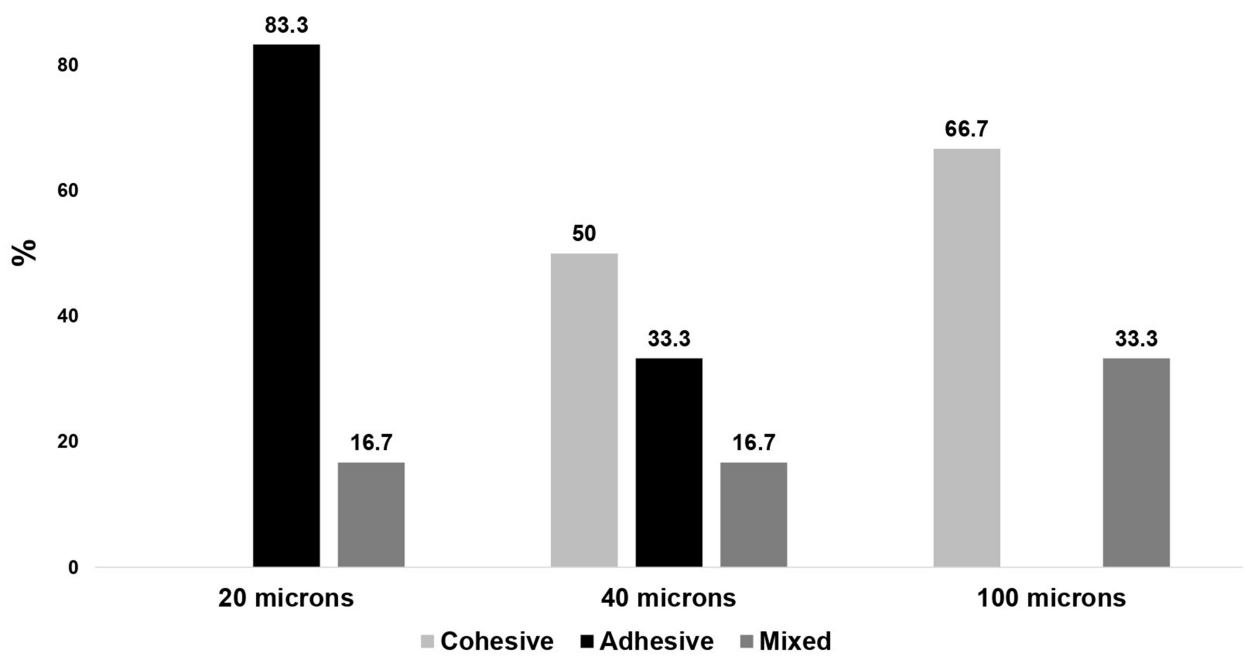

Figure 5 Distribution of failure type in fracture resistance among the study groups.

is uniformly bonded to a less stiff material, namely cement, high tensile stresses are generated within the ceramic at the ceramic cement interface, just beneath the load. ${ }^{21} \mathrm{~A}$ thicker cement thickness allows the ceramic to deform more into the cement as a compressive force is applied to it, than a thinner cement. Consequently, less force is required for the ceramic to fracture. ${ }^{11}$

Although the mean value of fracture strength was not affected in this study, the type of failure definitely was. The veneers with the lowest cement space $(20 \mu \mathrm{m})$ showed the highest percentage of adhesive failures, as opposed to no adhesive failures in the group with a $100-\mu \mathrm{m}$ digital die spacer setting. These findings are contrary to those reported by Ghasemi et al, who found that an increase in cement thickness resulted in reduced stress within the cement itself, and had an insignificant relationship on the stresses within the tooth or ceramic. ${ }^{22}$ The reduced stresses in resin cement can be related to the mechanical properties of the cement itself. Resin cements tend to have a low elastic modulus, which make them flexible and less likely 
Table 2 Tukey's Post Hoc Test Comparing the Failure Modes in Fracture Resistance Among the Study Groups

\begin{tabular}{|l|l|l|l|}
\hline & Group & $\begin{array}{l}\text { Compared } \\
\text { to }\end{array}$ & $\boldsymbol{P}$ value \\
\hline $\begin{array}{l}\text { Digital Die Spacer } \\
\text { Thickness }\end{array}$ & $\mathbf{2 0}$ microns & 40 microns & 0.117 \\
\cline { 2 - 4 } & & 100 microns & $0.009 *$ \\
\cline { 2 - 4 } & $\mathbf{4 0}$ microns & 100 microns & 0.290 \\
\hline
\end{tabular}

Notes: *Indicates a statistically significant difference at $p$ value $\leq 0.05$.

to fracture. ${ }^{23}$ In the present study, the majority of failures for the $40 \mu \mathrm{m}$ and $100 \mu \mathrm{m}$ cement thicknesses were either cohesive or mixed. Therefore, it can be argued that if greater cement thicknesses really had a reduced impact on the stress level of the cement and was insignificant in ceramic, such a large discrepancy in the failure distribution would not exist. The results of the present study correspond more closely to those of a study conducted by Wimmer et al where increased cement thickness had an impact on the framework of zirconium fixed prosthesis, thus causing cohesive failures within the ceramic. $^{23}$ However, it is important to mention that a restoration within the oral cavity is exposed to other types of mechanical forces, namely shear and tensile, and that compression comprises just one event that occurs during mastication. A successful restoration must have the appropriate criteria to withstand these forces. That said, even though fracture resistance was not influenced by an increase in cement space, previous studies have shown that shear bond strength is. ${ }^{8,9}$ Increased cement thicknesses beyond 40 $\mu \mathrm{m}$ significantly decrease bond strength. ${ }^{8,9}$ Therefore, for the sake of survival of the restoration, it is preferable to keep the digital die spacer settings approximately within the range of $25-40 \mu \mathrm{m}$, as defined by the American Dental Association. $^{24}$

\section{Conclusion}

Within the limitations of this study, it can be concluded that the value of digital die spacer settings did not affect the fracture resistance of lithium disilicate CAD veneers.

\section{Disclosure}

The authors have no conflicts of interests for this work to disclose. This research did not receive any specific grant from funding agencies in the public, commercial, or notfor-profit sectors.

\section{References}

1. Nejatidanesh F, Savabi G, Amjadi M, Abbasi M, Savabi O. Five year clinical outcomes and survival of chairside CAD/CAM ceramic laminate veneers - a retrospective study. J Prosthodont Res. 2018;62(4):462-467. doi:10.1016/j.jpor.2018.05.004

2. Seymour KG, Cherukara GP, Samarawickrama DYD. Stresses within porcelain veneers and the composite lute using different preparation designs. $J$ Prosthodont. 2001;10(1):16-21. doi:10.1111/j.1532849x.2001.00016.x

3. Fleming GJP, Maguire FR, Bhamra G, Burke FM, Marquis PM. The strengthening mechanism of resin cements on porcelain surfaces. $J$ Dent Res. 2006;85(3):272-276. doi:10.1177/154405910608500313

4. Spazzin AO, Guarda GB, Oliveira-Ogliari A, Leal FB, CorrerSobrinho L, Moraes RR. Strengthening of porcelain provided by resin cements and flowable composites. Oper Dent. 2016;41 (2):179-188. doi:10.2341/15-025-L

5. Penteado M, Mendes Tribst J, Dal Piva A, et al. Influence of different restorative material and cement on the stress distribution of ceramic veneer in upper central incisor. Indian J Dent Res. 2020;31(2):236. doi:10.4103/ijdr.IJDR_150_18

6. Rojpaibool T, Leevailoj C. Fracture resistance of lithium disilicate ceramics bonded to enamel or dentin using different resin cement types and film thicknesses. J Prosthodont. 2017;26(2):141-149. doi:10.1111/jopr.12372

7. Al-Dwairi ZN, Alkhatatbeh RM, Baba NZ, Goodacre CJ. A comparison of the marginal and internal fit of porcelain laminate veneers fabricated by pressing and CAD-CAM milling and cemented with 2 different resin cements. J Prosthet Dent. 2019;121 (3):470-476. doi:10.1016/j.prosdent.2018.04.008

8. Cho SH, Chang WG, Lim BS, Lee YK. Effect of die spacer thickness on shear bond strength of porcelain laminate veneers. $J$ Prosthet Dent. 2006;95(3):201-208. doi:10.1016/j.prosdent.2005.12.011

9. Sabarinathan S, Sreelal T, Rajambigai AAS. Evaluation of influence of die spacer thickness on the shear bond strength of porcelain laminate veneers: an in-vitro study. Indian J Stomatol. 2016;7 (2):42-47.

10. Sagsoz NP, Yanikoglu N. Evaluation of the fracture resistance of computer-aided design/computer-aided manufacturing monolithic crowns prepared in different cement thicknesses. Niger $J$ Clin Pract. 2018;21(4):417-422. doi:10.4103/njcp.njcp_137_17

11. Tuntiprawon M, Wilson PR. The effect of cement thickness on the fracture strength of allceramic crowns. Aust Dent J. 1995;40 (1):17-21. doi:10.1111/j.1834-7819.1995.tb05607.x

12. Linhares LA, Pottmaier LF, Lopes GC. Fracture resistance of veneers in premolars. Eur J Dent. 2018;12(2):191-198. doi:10.4103/ejd. ejd $349 \quad 17$

13. Liu HL, Lin CL, Sun MT, Chang YH. Numerical investigation of macro- and micro-mechanics of a ceramic veneer bonded with various cement thicknesses using the typical and submodeling finite element approaches. J Dent. 2009;37(2):141-148. doi:10.1016/j. jdent.2008.10.009

14. Toman M, Cal E, Türkün M, Ertuğrul F. Bond strength of glassceramics on the fluorosed enamel surfaces. J Dent. 2008;36(4):281-286. doi:10.1016/j.jdent.2008.01.006

15. Karntiang P, Leevailoj C. Effect of resin cement thickness on compressive fracture resistance of enamel-bonded ceramic. CU Dent $J$. 2014;37:161-170.

16. Scherrer SS, de Rijk WG, Belser UC, Meyer JM. Effect of cement film thickness on the fracture resistance of a machinable glassceramic. Dent Mater. 1994;10(3):172-177. doi:10.1016/01095641(94)90028-0

17. Venturini AB, Wandscher VF, Marchionatti AME, et al. Effect of resin cement space on the fatigue behavior of bonded CAD/CAM leucite ceramic crowns. $J$ Mech Behav Biomed Mater. 2020;110:103893. doi:10.1016/j.jmbbm.2020.103893 
18. Reich S, Uhlen S, Gozdowski S, Lohbauer U. Measurement of cement thickness under lithium disilicate crowns using an impression material technique. Clin Oral Investig. 2011;15(4):521-526. doi:10.1007/s00784-010-0414-x

19. Tribst JPM, Dal Piva AMO, Penteado MM, Borges ALS, Bottino MA. Influence of ceramic material, thickness of restoration and cement layer on stress distribution of occlusal veneers. Braz Oral Res. 2018;32:e118. doi:10.1590/1807-3107bor-2018.vol32.0118

20. May LG, Kelly JR, Bottino MA, Hill T. Effects of cement thickness and bonding on the failure loads of $\mathrm{CAD} / \mathrm{CAM}$ ceramic crowns: multi-physics FEA modeling and monotonic testing. Dent Mater. 2012;28(8):e99-e109. doi:10.1016/j.dental.2012.04.033

21 . Kelly JR. Clinically relevant approach to failure testing of allceramic restorations. J Prosthet Dent. 1999;81(6):652-661. doi:10.1016/ S0022-3913(99)70103-4
22. Ghasemi S, Babaloo AR, Negargar SAS, Amini S. The effect of cement thickness and preparation design on stress level and stress distribution in maxillary central incisor restored by laminate veneers-a finite element analysis. Artic J Evol Med Dent Sci. 2019;8(10):712-718. doi:10.14260/jemds/2019/157

23. Wimmer T, Erdelt K-J, Raith S, Schneider JM, Stawarczyk B, Beuer F. Effects of differing thickness and mechanical properties of cement on the stress levels and distributions in a three-unit zirconia fixed prosthesis by FEA. J Prosthodont. 2014;23(5):358-366. doi:10.1111/jopr.12125

24. Langham S, Simon JF, Tantbirojn D, Redmond D, Langham S. The importance of the cement spacer for proper crown seating. Int J Comput Dent. 2017;20(3):275-285.

\section{Publish your work in this journal}

Clinical, Cosmetic and Investigational Dentistry is an international, peer-reviewed, open access, online journal focusing on the latest clinical and experimental research in dentistry with specific emphasis on cosmetic interventions. Innovative developments in dental materials, techniques and devices that improve outcomes and patient satisfaction and preference will be highlighted. The manuscript management system is completely online and includes a very quick and fair peer-review system, which is all easy to use. Visit http://www.dovepress.com/testimonials.php to read real quotes from published authors. 